\title{
December 2001
}

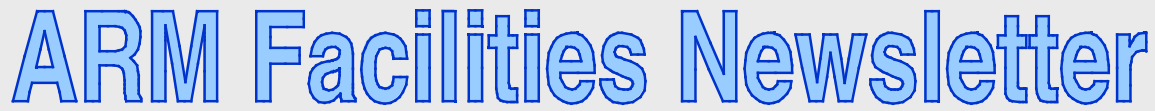

A N L / ER / N L-01-12

\section{Water Cycle Pil ot Study}

To learn more about Earth's water cycle, the U.S. Department of Energy (DOE) has established a multi-laboratory science team representing five DOE national laboratories: Argonne, Brookhaven, Lawrence Berkeley, Los Alamos, and Oak Ridge. The science team will conduct a threeyear Water Cycle Pilot Study within the ARM SGP CART site, primarily in the Walnut River Watershed east of Wichita, Kansas.

The host facility in the Walnut River Watershed is the Atmospheric Boundary Layer Experiments (ABLE) site. The ABLE capabilities to be used for the current effort were developed under funding from the DOE office that supports both the ARM Program and closely related investigations of the carbon and water cycles, as well as funding from the National Aeronautics and Space Administration and Argonne National Laboratory.

The water cycle is important in greenhouse warming and climate change. The crucial problem of making water cycle models more accurate will challenge the combined capabilities of the laboratories involved. These capabilities include complementary expertise and resources in highperformance computing, advanced measurement techniques, experimental sites, and databases.

Researchers will investigate the water cycle and the effect of the ecosystem on variability in the water cycle over time and space. The first step in the study, model evaluation, will determine how well current models simulate interactions between the atmosphere, land, and hydrologic processes. In this step, the investigators will compare measured meteorological values with numbers calculated by computer models.

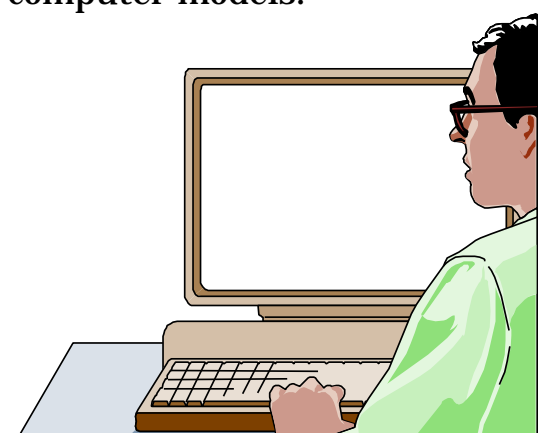

ARM Facilities Newsletter is published by Argonne National Laboratory, a multiprogram laboratory operated by The University of Chicago under contract W-31-109-Eng-38 with the U.S. Department of Energy.

Technical Contact: James C. Liljegren

Editor: Donna J. Holdridge 
A second area of study, identification of the paths water takes as it moves through the water cycle, will involve measurement and tracking of water isotopes. A water isotope is a naturally occurring water molecule that has a different number of neutrons (and thus a different molecular weight) than a standard water molecule. The water isotope and standard water have similar chemical properties, but researchers can differentiate the two by their molecular weights. Thus, water isotopes can be used as tracers to track water flow and paths. Investigators will hydrologic variability in more depth, looking for links with human activity and effects of ecosystem changes. Current water cycle models are not detailed enough to make adequate predictions of the regional water balance, and thus improving these models is a priority.

The Water Cycle Pilot Study is designed to validate DOE's investigational methods and demonstrate the agency's unique capabilities before the second study begins. The SGP CART site is, once again, proving its worth as a well-equipped,

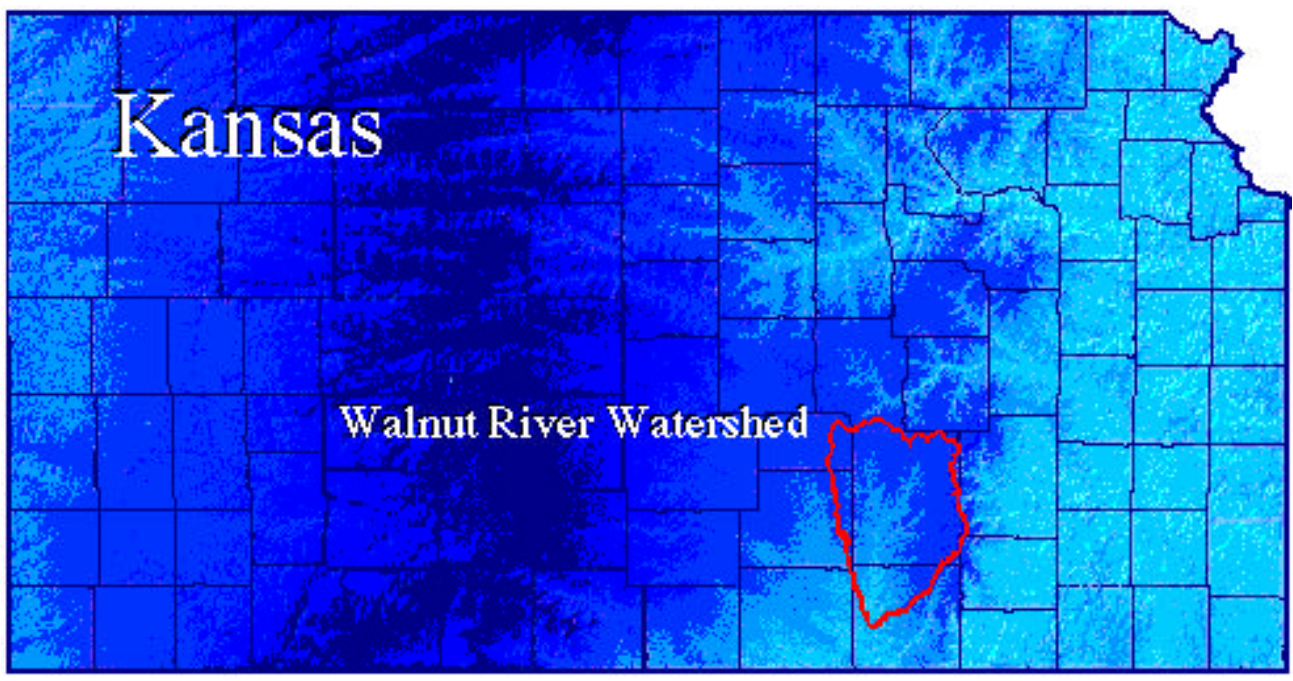

Figure 1. The Walnut River Watershed, outlined in red, will serve as the focus area for the Department of Energy's Water Cycle Pilot Study.

measure water isotopes in samples of water vapor, precipitation, runoff, and soil and plant water from the Walnut River Watershed, then use the measurements to evaluate water isotope computer models.

The Water Cycle Pilot Study is a precursor to DOE's proposed U.S. Water Cycle Program. The proposed program will investigate global and regional unique outdoor laboratory meeting a crucial need in environmental research. Much of the information required to complete the pilot study is already being collected as part of the long-term ARM Program. The collaborative effort DOE is focusing on the investigation is expected to result in major progress toward the challenging science goal of accurate modeling of the water cycle. 